\title{
A interpretação de pistas prosódicas na aposição de atributos em sentenças ambíguas do PB
}

\author{
Prosodic cues interpretation for attribute apposition of \\ ambiguous sentences in BP
}

\author{
Aline Alves Fonseca* \\ Universidade Federal de Minas Gerais \\ José Olímpio de Magalhães** \\ Universidade Federal de Minas Gerais
}

\begin{abstract}
With the aim to investigate the prosodic cues influences in the interpretation of ambiguous sentences that present a NP1 - VP NP2 - ATTRIBUTE structure, as in "O pai visitou o filho embriagado" ("The drunk father visited the son" / "The father visited the drunk son"), some tests were applied to four subjects of an earlier experiment where they were invited to reinterpret their own reading aloud. These subjects were also invited to produce another reading aloud, now giving explicit prosodic cues to indicate the attribute apposition - to the NP1 or to the NP2. The attribute apposition of the earlier reading aloud and this re-reading were interpreted by other groups of subjects. We present here the results and analyses of this experiment.
\end{abstract}

Keywords

Ambiguous sentences, Reading aloud, Prosodic cues. 


\section{Resumo}

Buscando investigar as influências da prosódia na interpretação de sentenças ambíguas do tipo SN1 - SV - SN2 - ATRIBUTO, como em "O pai visitou o filho embriagado", aplicamos testes em que quatro informantes de um experimento anterior reinterpretaram sua própria leitura e, em seguida, leram novamente as sentenças marcando prosodicamente uma aposição para o atributo (referindo-se ao SN1 ou ao SN2) para que outros grupos de ouvintes interpretassem a aposição do atributo tanto dessas sentenças agora lidas com uma aposição intencional, quanto delas antes lidas sem essa preocupação. Apresentamos aqui os resultados e análises desse experimento.

\section{Palavras-chave}

Sentenças ambíguas, Leitura em voz alta, Pistas prosódicas. 


\section{Introdução}

s teorias psicolingüísticas em Processamento de Frases têm como $A$ objeto de estudo principal o parser, ${ }^{1}$ que é o responsável pelos 11 procedimentos mentais que fazemos para estruturar e para atribuir significado às sentenças que lemos ou ouvimos. "O parser é parte integrante dos processos de produção e compreensão da linguagem e também é conhecido como 'mecanismo humano de processamento de frases' (Human Sentence Processing Mechanism - HSPM)" (MAIA; FINGER, 2005, p. 15).

Na tentativa de explicar como somos capazes de produzir e compreender a linguagem (falada ou escrita), existem vários modelos teóricos que adotam paradigmas opostos em relação ao processador: ${ }^{2}$ a) ou há um comprometimento com uma estrutura sintática mínima em construção e, caso o processador encontre uma incompatibilidade com essa estrutura comprometida, faz-se necessário um processo de reanálise ao fim do processamento (comprometimento mínimo e rápido versus delay); b) ou há uma computação paralela de todas as possibilidades de estruturação sintática para a sentença que está sendo lida/ouvida, ou seja, se existe uma ambigüidade local, o processador "leva em conta" as duas (ou mais) estruturas sintáticas possíveis até que todo o material da sentença tenha sido reconhecido para, por fim, determinar qual é a estrutura mais adequada para a sentença em questão (o processo de compreensão é um processo de satisfação de condições que são impostas pela seqüência de palavras e pelo conhecimento sobre como tais seqüências devem ser interpretadas).

O primeiro paradigma descrito acima, embora com visões diferentes do processamento de sentenças (comprometimento mínimo e rápido versus delay), pressupõe que o conhecimento e o acesso lingüísticos podem ser adequadamente caracterizados em termos da manipulação de cadeias de símbolos, através de princípios e regras. Já o segundo paradigma, oposto aos modelos simbólicos da linguagem e da cognição humanas, baseia-se mais na experiência: o processo de compreensão é um processo de satisfação de condições que são impostas pela 
sequiência de palavras e pelo conhecimento sobre como tais seqüências devem ser interpretadas. Essa abordagem, calcada na experiência, pressupõe conexões em rede que permitem que os inputs atualizem a representação da frase.

Este artigo segue um direcionamento mais próximo do primeiro paradigma, assumindo, pois, uma hipótese incrementacional através da (TGP) Teoria Garden-Path (FRAZIER; FODOR, 1978; FRAZIER, 1979; FRAZIER; RAYNER, 1982), ou Teoria do Labirinto. ${ }^{3}$ A TGP assume que o parser, além de serial, é encapsulado, ou seja, opera somente com seu conhecimento sintático, não sofrendo interferência de outros campos como o semântico, o pragmático, o prosódico, etc. Para a TGP, o parser usa um conjunto de regras universais de boa formação da língua para guiar a construção da estrutura sintática da sentença que está sendo processada.

Entre os princípios que conduzem o parser no momento do processamento de sentenças, dois se aplicam mais diretamente ao nosso estudo:

- Minimal Attachment (Aposição Mínima): “Attach incoming material into the phrase-marker being constructed using the fewest nodes consistent with the well-formedness rules of the language under analysis."4 (FRAZIER, 1979, p. 24)

- Late Closure (Encerramento Tardio): "When possible, attach incoming material into the phrase or clause currently being parsed (i.e., the lowest possible nonterminal node dominating the last item analyzed)" "5 (FRAZIER, 1979, p. 33).

Embora seguindo a TGP, questionamos se a informação mínima e rápida para o processamento é sempre, primordialmente, sintática/estrutural ou se outras informações gramaticais, como a prosódica, podem conduzir o parsing.

AHPI (Hipótese da Prosódia Implícita, FODOR, 1998 e 2002) propõe que, em situações de ambigüidade estrutural, as pistas prosódicas podem influenciar diferentes resoluções sintáticas, independentemente do momento do acesso prosódico para o processamento. A hipótese é apresentada nos seguintes termos:

- In silent reading, a default prosodic contour is projected onto the stimulus, and it may influence syntactic ambiguity resolution. Other things being equal, the parser favors the syntactic analysis associated with the most natural (default) prosodic contour for the construction. ${ }^{6}$ (FODOR, 2002, 2005). 
Tal hipótese pode ser encontrada de forma embrionária no modelo de parsing conhecido como Sausage Machine, a "máquina de salsichas" (FRAZIER; FODOR, 1978). Conforme apontado por Lovrič (2003), no modelo de 1978, essa tendência era analisada como decorrente de pressão da memória de trabalho, tendo sido reinterpretada em Fodor, 1998, como conseqüência da segmentação prosódica.

Nossa hipótese, calcada na HPI, é de que o falante/ouvinte pode induzir o processamento sintático da sentença, pelo uso explícito de pistas prosódicas, ou seja, que pistas prosódicas mudam a segmentação prosódica da sentença, promovendo para o ouvinte um possível rearranjo sintático capaz de direcionar o parsing.

A proposta de Fodor fornece uma resposta ao questionamento levantado em Cuetos \& Mitchell, 1988, sobre a universalidade do princípio Late Closure (Princípio da Aposição Local), anteriormente descrito. De modo geral, haveria uma tendência nas línguas para 'colar' embaixo os constituintes mais leves, que buscariam um hospedeiro local. Os constituintes mais pesados, por outro lado, seriam mais autônomos para buscar hospedeiros não locais, dependendo dos padrões prosódicos de cada língua.

No caso da aposição das orações relativas (OR), como em "Alguém atirou no empregado da atriz que estava na varanda", por exemplo, (LOURENÇOGOMES; MAIA; MORAES, 2005; LORENÇO-GOMES, 2003) uma língua que favorecesse uma quebra prosódica na margem esquerda da relativa, logo após o N2, deveria facilitar sua aposição alta, não-local. Por outro lado, uma língua que preferisse a continuidade prosódica entre o N2 e a oração relativa, deveria favorecer a sua aposição baixa. Em outras palavras, a proposta de Fodor é a de que as línguas que preferem a aposição não-local à OR são aquelas cujas restrições de interface favorecem uma pausa prosódica antes da OR, pausa essa que poderia ser entendida como marcadora de uma descontinuidade estrutural na árvore sintática.

No final do artigo, Fodor (2002) sugere ainda uma série de construções em que a Hipótese da Prosódia Implícita pode vir a ser testada, ampliando o seu escopo para além das ORs, tais como a concorrência e as compensações entre comprimento, foco, força ilocucionária, alinhamento nas margens e a configuração arbórea.

Em busca de evidências que comprovassem nossa hipótese de que o falante/ ouvinte pode induzir o processamento sintático da sentença, pelo uso 
explícito de pistas prosódicas, ou seja, que pistas prosódicas mudam a segmentação prosódica da sentença, promovendo para o ouvinte um possível rearranjo sintático capaz de direcionar o parsing e, conseqüentemente, a interpretação da sentença no sentido de uma Aposição Não-Local, trabalhamos com as seguintes "segmentações" prosódicas, ${ }^{7}$ analisadas utilizando-se o Programa de Análise Acústica PRAAT, versão 4.2.07 (BOERSMA; WEENICK, 2005):

a. Elevação da frequiência fundamental em SN1 e no Atributo,

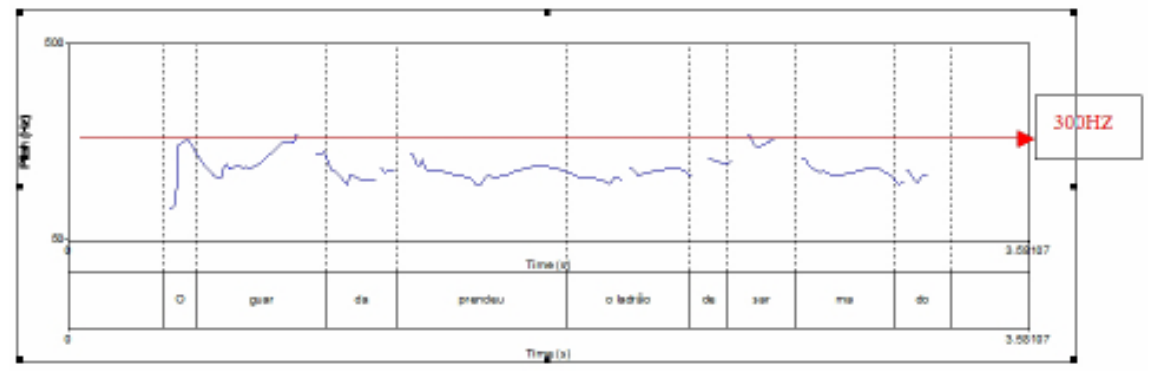

FIGURA 1 - A sentença "O guarda prendeu o ladrão desarmado" com elevação de F0 no SN1 'GUARda' e no Atributo ‘dcSARmado'.

b. Alongamento da sílaba tônica do Atributo

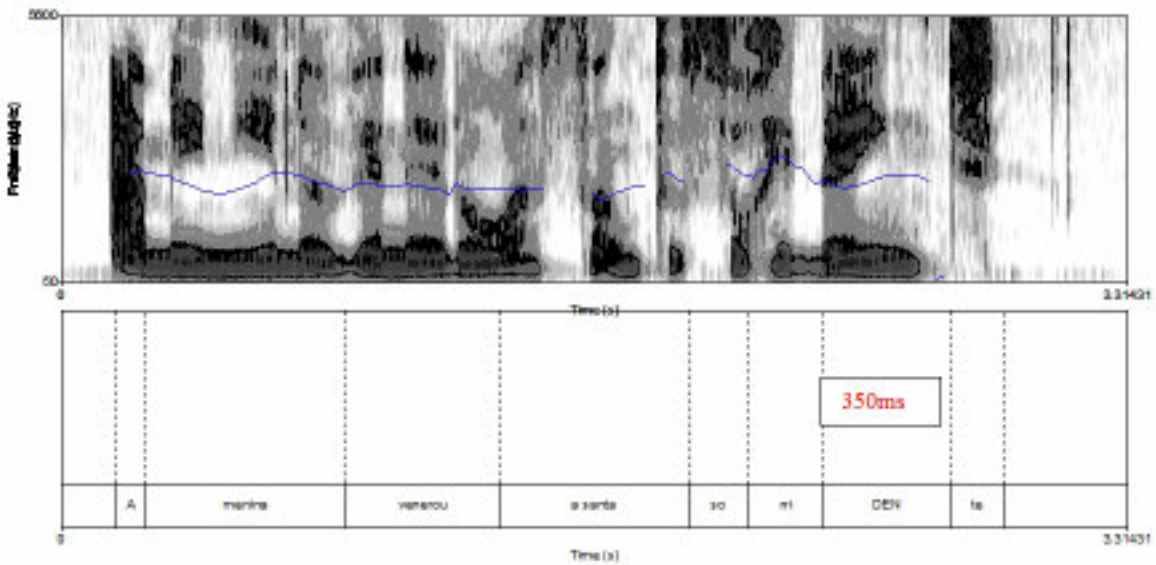

FIGURA 2 - A sentença "A menina venerou a santa sorridente" com alongamento na vogal tônica do Atributo 'SorriDENte'. 
c. Pausa silenciosa entre SN2 e o Atributo.

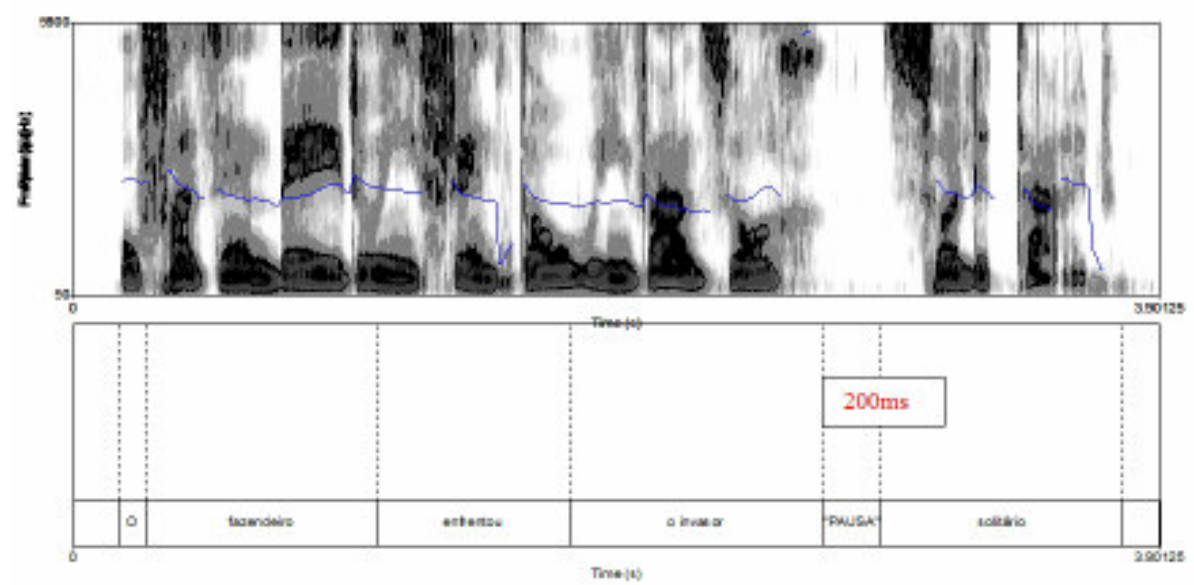

FIGURA 3 - A sentença "O fazendeiro enfrentou o invasor solitário" com pausa após o SN2 'o invasor'.

Todas essas pistas foram comparadas a uma situação neutra (inexistência de pistas evidentes como as citadas) que favorece a interpretação default da sentença, ou seja, a Aposição Local, como exemplificado abaixo:

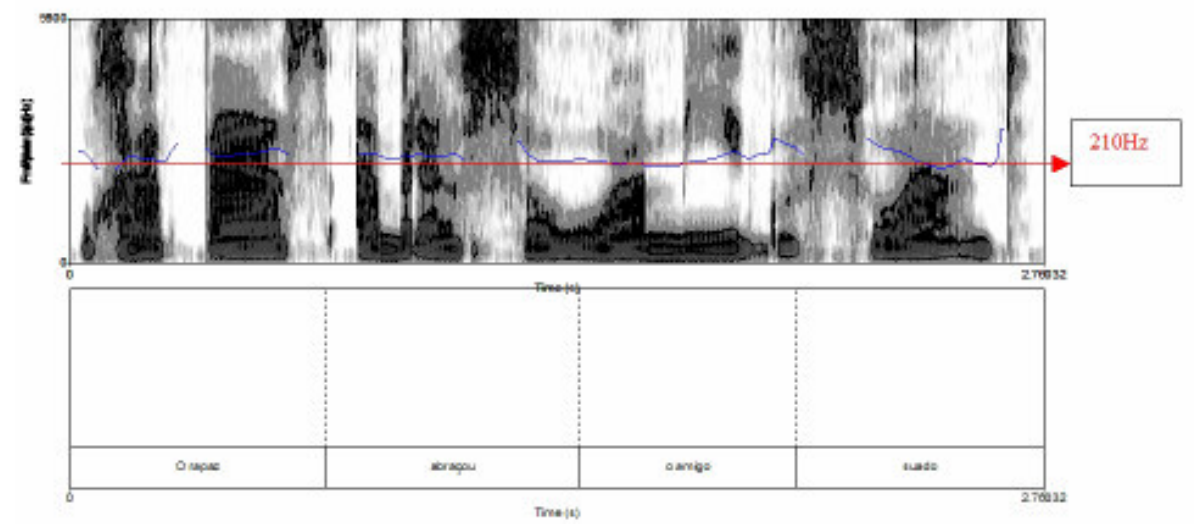

FIGURA 4 - A sentença "O rapaz abraçou o amigo suado" com leitura neutra.

Portanto, o pressuposto é de que a prosódia pode não só influenciar, como direcionar a interpretação sintática de sentenças. 


\section{Experimento anterior}

Com base nesse pressuposto, Magalhães \& Maia (2006a, b), em estudo que não incluiu metodologia on-line, demonstraram que, pela manipulação prosódica, o Princípio da Aposição Local pode ser enfraquecido ou, até mesmo, reforçado na compreensão de construções com adjuntos adnominais ambíguos em português, como na frase de estrutura sintática ambígua do tipo SN1 - SV - SN2 - ATRIBUTO, "O motorista atropelou o pedestre bêbado".

O estudo examinou a compreensão de leitura de 24 sentenças do tipo descrito acima, entremeadas por 48 distratoras, em uma tarefa de interpretação off-line. As frases ou partes delas apareciam uma a uma, para teste de leitura automonitorada $^{8}$ em tela de computador, utilizando-se o programa PSYSCOPE (http://psyscope.psy.cmu.edu/). Foram organizados quatro grupos de 10 sujeitos cada um, tendo sido as frases divididas de quatro maneiras, como a seguir, de forma que um grupo não tivesse acesso à mesma exposição do outro: ${ }^{9}$

(i) frases segmentadas em duas partes não-cumulativas, com uma segmentação após o VERBO, como em

O motorista atropelou / o pedestre bêbado;

(ii) frases segmentadas em duas partes não-cumulativas, com uma segmentação após o SN OBJETO, como em

O motorista atropelou o pedestre / bêbado;

(iii) as mesmas frases, agora SEM SEGMENTAÇÃO, para leitura silenciosa;

(iv) as mesmas frases, agora SEM SEGMENTAÇÃO, para leitura em voz alta.

Os sujeitos controlavam o aparecimento, na tela, das frases completas ou das partes segmentadas das frases, pela barra de espaço do teclado. No final das frases, os sujeitos deviam decidir-se, o mais rápido possível, por uma de duas interpretações, pressionando botões do teclado, previamente marcados com as duas opções.

Nas frases SEM SEGMENTAÇÃO, as alternativas para interpretação apareciam quatro segundos após as mesmas, e os sujeitos deviam também se decidir, o mais rápido possível, por uma das duas interpretações. ${ }^{10}$ Os resultados da 
leitura silenciosa e em voz alta das frases sem segmentação (sem direcionamento prosódico) podem ser vistos na Tabela 1 com respectivo Gráfico 1, a seguir:

TABELA 1

Preferência de Aposição em frases não-segmentadas

\begin{tabular}{lcccc}
\hline $\begin{array}{l}\text { Frases não- } \\
\text { segmentadas }\end{array}$ & $\begin{array}{c}\text { Aposição } \\
\text { Não-local }\end{array}$ & \multicolumn{3}{c}{$\begin{array}{c}\text { Aposição } \\
\text { Local }\end{array}$} \\
\hline Leit. Silenc. & 69 & $28,75 \%$ & 171 & $71,25 \%$ \\
Leit. Voz alta & 81 & $33,75 \%$ & 159 & $66,25 \%$ \\
\hline
\end{tabular}

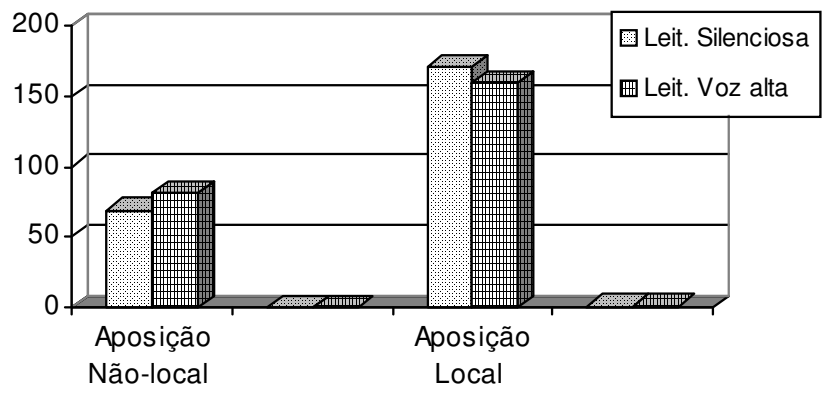

GRÁFICO 1 - Tipo de leitura e tipo de escolha de Aposição

Os dados analisados indicaram também que a segmentação (direcionamento prosódico) confirma a utilização de pistas prosódicas na decisão por uma aposição. Os resultados da tarefa de interpretação, na leitura silenciosa de frases segmentadas, indicaram que há interações significativas entre o tipo de segmentação e a escolha pela aposição não-local ou pela aposição local, em comparação com a escolha nas frases não-segmentadas, conforme mostrado anteriormente. A segmentação após o verbo (TAB. 2, abaixo) aumenta significativamente as taxas de aposição local em comparação com a taxa de aposição local na leitura silenciosa sem segmentação (195 vs. 171 p=0.010), ${ }^{11}$ e a segmentação depois do SN Objeto, ou SN2, (TAB. 2, abaixo) diminui significativamente a taxa da aposição local, em comparação com a aposição local na leitura silenciosa sem segmentação (145 vs. $171 \mathrm{p}=0.012):^{12}$ 
TABELA 2

Preferência de Aposição em frases segmentadas

\begin{tabular}{lcccc}
\hline $\begin{array}{l}\text { Frases } \\
\text { segmentadas }\end{array}$ & $\begin{array}{c}\text { Aposição } \\
\text { Não-local }\end{array}$ & \multicolumn{3}{c}{$\begin{array}{c}\text { Aposição } \\
\text { Local }\end{array}$} \\
\hline Após V & 45 & $18,75 \%$ & 195 & $81,25 \%$ \\
Após SN2 & 95 & $39,58 \%$ & 145 & $60,42 \%$ \\
\hline
\end{tabular}

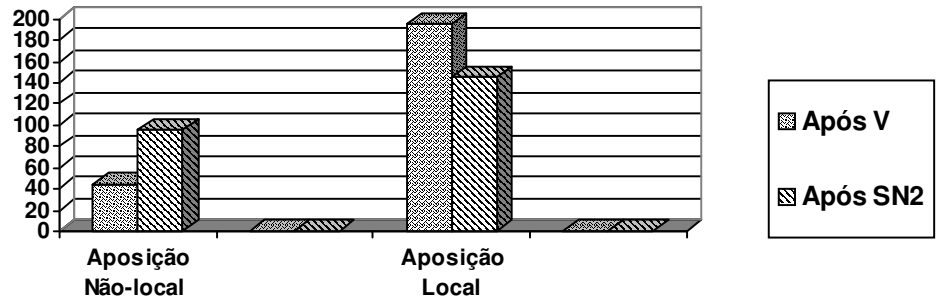

GRÁFICO 2 - Tipo de leitura e tipo de escolha de Aposição

Portanto, esse experimento mostrou que o Princípio de parsing de Aposição Local é o default na compreensão de frases como as testadas, mas demonstrou, também, que, manipulando a segmentação delas, o princípio pode ser enfraquecido ou reforçado, indicando que a informação prosódica pode influenciar na compreensão, o que seria evidência em favor da Hipótese da Prosódia Implícita. O experimento mostrou ainda que, na leitura em voz alta, as pistas prosódicas de elevação da freqüência fundamental em SN1 e no Atributo, de alongamento da sílaba tônica do Atributo e de pausa silenciosa entre SN2 e o Atributo interferem na decisão interpretativa, e que a leitura silenciosa das mesmas sentenças tem resultado não-significativamente diferente da leitura em voz alta, o que comprovaria que a prosódia da frase é mentalmente assumida pelos leitores e pode afetar a resolução da ambigüidade sintática.

Em estudo semelhante, intitulado Prosodic Cues for SyntacticallyMotivated Junctures, Chow (2005), relata a maneira com que falantes do cantonês empregam pistas prosódicas para marcar junturas sintáticas de sentenças que apresentam dupla interpretação, no sentido de prestigiar um ou outro significado da sentença. Pela aplicação de um experimento de leitura em voz alta em que o contexto levava a uma ou outra interpretação, o autor descobre, pela análise 
prosódica das gravações, que os falantes dessa língua empregam três marcadores prosódicos de juntura: pausas (97\%), retomada de pitch (88\%) e alongamento antes de fronteira (64\%). Como vemos, esta última estratégia mostrou-se a menos frequiente e as duas outras foram largamente utilizadas pelos falantes, sendo a pausa a preferida.

\section{Novo experimento}

Com base nesses resultados, quase dez meses após a aplicação dos testes, entrevistamos novamente quatro sujeitos do experimento anterior, solicitando-lhes as seguintes tarefas:

1) Ouvir, uma vez, TODAS as frases experimentais que gravou. Em seguida, ouvir uma por uma e se decidir, COM BASE NA PROSÓDIA DA LEITURA QUE FEZ, se teria marcado (a) aposição alta, ou (b) aposição baixa, assinalando com um X, numa folha contendo APENAS os números das frases e as opções (a) ou (b). O sujeito pôde usar o tempo que achasse necessário, inclusive voltando e ouvindo a frase mais de uma vez.

2) Tendo em mão as frases com as respostas que deu no experimento anterior, LER FAZENDO A PROSÓDIA DE ACORDO COM A APOSIÇÃO ESCOLHIDA NAÉPOCA, de tal forma que, se alguém o ouvir, não tenha dúvida sobre a interpretação dada para a frase. O sujeito pôde cancelar a gravação da frase, quantas vezes quisesse, até chegar àquela que julgasse estar de acordo com a tarefa solicitada.

Ao propormos essas duas tarefas, tínhamos em mente os seguintes pressupostos: os resultados obtidos na primeira tarefa apontarão que as respostas, de forma significativa, NÃO coincidirão com aquelas dadas na $1^{\mathrm{a}}$. fase do experimento, pois deve haver diferenças no processamento da sentença na sua produção (leitura em voz alta) e na sua percepção (ouvir a própria voz ou a de outrem), além de haver fatores de ordem lingüística e não-lingüística influenciando nas escolhas de aposição em cada momento. Quanto à segunda tarefa, sua importância será a de podermos confirmar/rejeitar que, ao ler uma frase com intenção de dar uma determinada interpretação, um outro ouvinte dessa segunda leitura terá um maior índice de acertos na interpretação do significado da sentença, o que indicaria que pistas prosódicas intencionais definiriam a estrutura sintático-semântica da frase. 


\section{Metodologia do novo experimento}

Selecionamos quatro informantes do experimento anterior (Magalhães; Maia, 2006b), dois do sexo feminino, dois do sexo masculino, que foram solicitados a ouvir suas próprias leituras e escolher novamente uma aposição para o atributo das sentenças (Tarefa 1, citada anteriormente). Denominamos esse novo teste Teste de Percepção da Própria Leitura. Em seguida, os quatro informantes, após esse teste de percepção, foram solicitados a ler novamente as 24 sentenças de teste, aplicando uma prosódia que julgassem ser capaz de desfazer a ambigüidade da sentença, tendo em vista as aposições escolhidas por eles no experimento anterior (Tarefa 2).

Em seguida, trinta e dois informantes-ouvintes ${ }^{13}$ (oito para cada informanteleitor acima) foram solicitados a ouvir doze das vinte e quatro sentenças de teste, lidas espontaneamente pelos informantes leitores no experimento de Magalhães e Maia (2006b), e as doze outras sentenças lidas pelos informantes-leitores no novo experimento (regravação), ou seja, lidas com uma intenção interpretativa "marcada" prosodicamente (lidas na Tarefa 2, citada anteriormente). Esses trinta e dois informantes-ouvintes marcavam em uma folha de papel uma das duas opções de aposição, de acordo com a prosódia da leitura da sentença que estavam ouvindo. Reportaremos, a seguir, a análise dos resultados obtidos nas tarefas acima. Denominamos esse novo teste Teste de Percepção de Leitura Intencional.

\section{Resultados e análises}

Analisando os resultados doTeste de Percepção da Própria Leitura, examinamos acusticamente, utilizando o Programa PRAAT, versão 4.2.07, as pistas prosódicas espontâneas usadas pelos informantes-leitores e as coincidências de preferências de aposição de acordo com tais pistas prosódicas. ${ }^{14}$ Os resultados foram:

TABELA 3

Teste de Percepção - \% de Respostas coincidentes com a marcação de pista prosódica da leitura.

\begin{tabular}{cccc}
\hline Informante 1 & Informante 2 & Informante 5 & Informante 8 \\
\hline 12 & 12 & 11 & 13 \\
$50 \%$ & $50 \%$ & $45,83 \%$ & $54 \%$ \\
\hline
\end{tabular}


Conforme esperávamos, a reinterpretação dada pelos informantes (leitores do experimento anterior) não foi sensível à prosódia espontânea empregada por eles próprios na leitura realizada no experimento de Magalhães e Maia (2006b). Quando foram solicitados a escolher a aposição do atributo de acordo com a prosódia que empregaram na leitura espontânea (experimento anterior), as respostas coincidentes com as pistas prosódicas utilizadas ficaram em torno de 50\% (hipótese nula) para todos os quatro informantes. A nosso ver, os resultados percentuais neutros obtidos nessa tarefa apontam para três fatores: i. diferenças entre Produção (experimento anterior) e Percepção (da própria leitura); ii. influências de outros fatores de ordem lingüística e não-lingüística nas escolhas de aposição, em cada momento em que foi aplicado o experimento; iii. o não-uso propositado de pistas prosódicas, na leitura espontânea, para o direcionamento da interpretação, mantendo-se então a preferência pela aposição considerada default para a estrutura, ou seja, a Aposição Local.

No segundo teste, Teste de Percepção de Leitura Intencional, examinamos as pistas prosódicas acústicas usadas pelos leitores e a coincidência de respostas dadas pelos ouvintes de acordo com tal pista prosódica. Nas duas tabelas seguintes, mostramos de forma simplificada quais pistas prosódicas (e em qual porcentagem) foram usadas pelos informantes-leitores nas leituras Espontânea e Intencional. Em seguida, temos os resultados de coincidência da interpretação dos ouvintes com a pista prosódica empregada pelo informante-leitor, mostrados nos gráficos a seguir.

TABELA 4

Uso de Pistas Prosódicas na Leitura Intencional

\begin{tabular}{cccc}
\hline \multicolumn{4}{c}{ Leitura Espontânea - Uso de pistas Prosódicas } \\
\hline Informante-Leitor & Elevação do F0 & Alongamento & Pausa \\
\hline 1 & $33,3 \%$ & $14,3 \%$ & $52,4 \%$ \\
2 & $40 \%$ & $0 \%$ & $60 \%$ \\
5 & $15,4 \%$ & $30,8 \%$ & $53,8 \%$ \\
8 & $9 \%$ & $18 \%$ & $73 \%$ \\
\hline
\end{tabular}


TABELA 5

Uso de Pistas Prosódicas na Leitura Espontânea

\begin{tabular}{cccc}
\hline \multicolumn{4}{c}{ Leitura Intencional - Uso de pistas Prosódicas } \\
\hline Informante-Leitor & Elevação do F0 & Alongamento & Pausa \\
\hline 1 & $13,3 \%$ & $13,3 \%$ & $73,4 \%$ \\
2 & $70 \%$ & $20 \%$ & $10 \%$ \\
5 & $20 \%$ & $0 \%$ & $80 \%$ \\
8 & - & - & - \\
\hline
\end{tabular}

Os tipos de pistas prosódicas que encontramos nas leituras Espontânea e Intencional foram: pausa silenciosa após N2, elevação da F0 no SN1 e no atributo e alongamento da vogal tônica do atributo. Para esse teste não analisamos a percepção do ouvinte quanto à pista prosódica separadamente. Testamos apenas se o fato de existir ou não uma pista era perceptível ao ouvinte.

Nos gráficos adiante mostraremos a porcentagem de respostas dos ouvintes (Teste de Percepção de Leitura Intencional), coincidentes com o uso ou não-uso de pistas prosódicas pelos leitores (que leram aplicando uma prosódia que julgassem ser capaz de desfazer a ambigüidade da sentença):

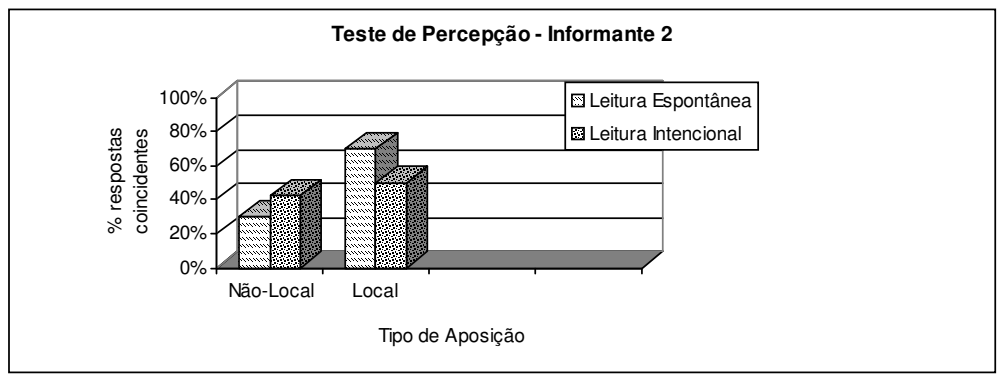

GRÁFICO 3 - \% de Respostas Coincidentes dos ouvintes com as Pistas Prosódicas utilizadas na leitura do Informante 2.

O fato de o maior índice de respostas coincidentes do grupo de ouvintes para a leitura do informante-Leitor 2 ser na Leitura Espontânea com Aposição Local (70\% no Gráfico 3), mostra-nos que esse informante-leitor não utilizou pistas prosódicas claras: os ouvintes tenderam para a marcação da aposição default, atestando o princípio de Late Closure. 


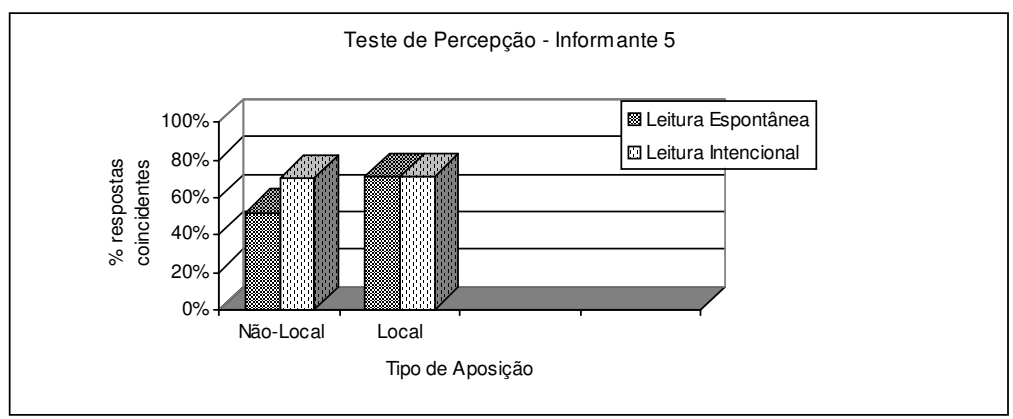

GRÁFICO 4 - \% de Respostas Coincidentes dos ouvintes com as Pistas Prosódicas utilizadas na leitura do Informante 5.

O informante-Leitor 5 conseguiu empregar pistas prosódicas mais claras. Os ouvintes conseguiram reconhecer sua intenção interpretativa em cerca de $70 \%$ da Leitura Intencional. O fato de essa porcentagem ser maior do que na Leitura Espontânea mostra-nos a mudança de comportamento do informanteleitor quando solicitado a marcar pela fala sua intenção de aposição. Vemos que, apesar de o Leitor 5 ter empregado pistas prosódicas em 12 sentenças na Leitura Espontânea (40\% de Elevação de F0 e 60\% de Pausa, conforme TAB. 4), estas não foram claras para os ouvintes: a coincidência de respostas ficou em 52\%, como podemos ver pelo Gráfico 4. Já as pistas empregadas nas sentenças da Leitura Intencional foram mais evidentes para os ouvintes, que coincidiram suas respostas com tais pistas em $70 \%$.

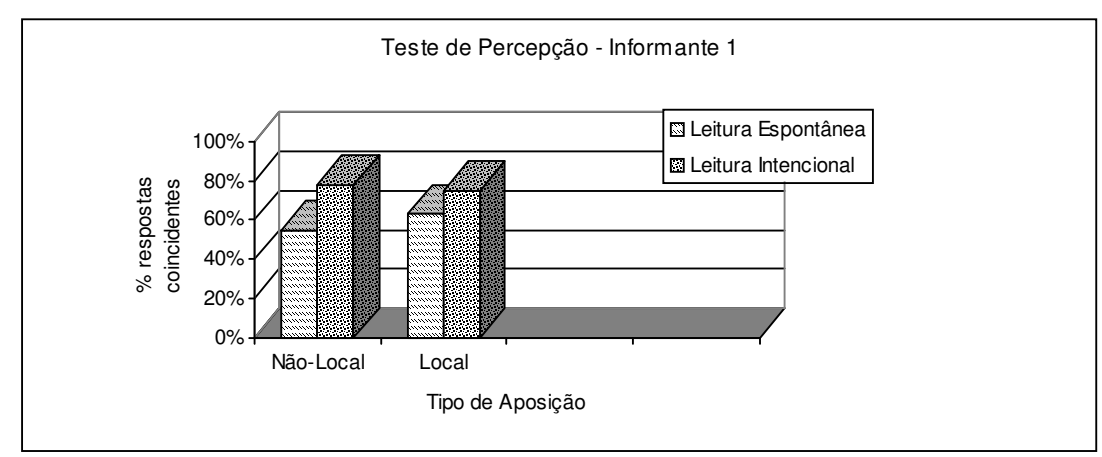

GRÁFICO 5 - \% de Respostas Coincidentes dos ouvintes com as Pistas Prosódicas utilizadas na leitura do Informante 1. 
O Informante-Leitor 1 foi o que realizou o maior número de pistas prosódicas que direcionavam a interpretação para a Aposição Não-Local. Foi também o que obteve mais êxito nessa tarefa. Os ouvintes reconheceram em mais de 75\% a intenção interpretativa desse informante-leitor em sua Leitura Intencional. Isso mostra-nos que, quando bem empregadas, as pistas prosódicas tornam-se fator inteligível ao ouvinte e podem influenciar a interpretação de sentenças com ambigüidades sintáticas.

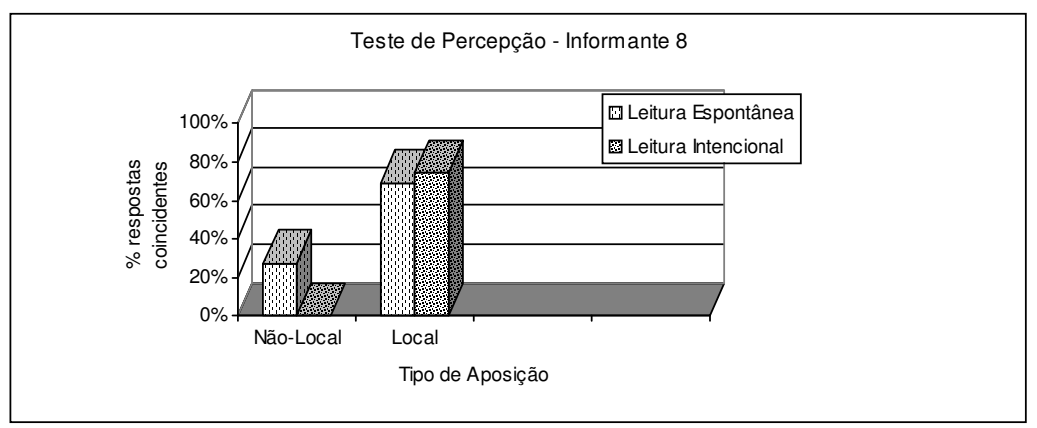

GRÁFICO 6 - \% de Respostas Coincidentes dos ouvintes com as Pistas Prosódicas utilizadas na leitura do Informante 8.

O informante-Leitor 8, como podemos verificar na Tabela 5, não empregou pistas prosódicas em sua Leitura Intencional. Esse leitor apenas fez uma leitura enumerativa, com prosódia neutra. Daí se explica o baixo índice de escolha, pelos ouvintes, da Aposição Não-Local (já que esta não é a escolha "default" dos informantes). Na Leitura Espontânea, foram empregadas pistas prosódicas em 11 sentenças (distribuídas em 9\% de Elevação de F0, 18\% de Alongamento no Atributo e 73\% de Pausa após SN2, conforme Tabela 4), mas estas não foram percebidas pelos ouvintes, é o que comprovam os dados do gráfico 6, apenas $27 \%$ de respostas dos ouvintes coincidiram com essas sentenças "produzidas" com pistas prosódicas para Aposição Não-Local. O maior índice de escolha pela Aposição Local mais uma vez corrobora que esta é a escolha default para a estrutura sintática em estudo, confirmando o princípio de Late Closure. Apenas o uso de pistas prosódicas claras e bem direcionadas pode modificar o padrão de escolha dos informantes.

Esses dados levam-nos a pensar que há graus diferentes de marcação de pistas prosódicas: quando o falante quer provocar um processamento através da prosódia (com a finalidade, talvez, de desfazer uma possível ambigüidade) ele produz 
pistas mais acuradas; caso, no entanto, outras informações de ordem lexical, pragmática ou de sintaxe default sejam suficientes, a prosódica pode ser menos trabalhada. Há também aqueles que não conseguem empregar, intencionalmente, uma estrutura prosódica boa o suficiente para desfazer uma ambigüidade estrutural. O exercício metalingüístico que solicitamos aos leitores mostrou-nos isso. Vale ressaltar aqui que nenhum dos leitores desse experimento foi treinado ou instruído sobre o que são pistas prosódicas ou como devem ser empregadas na leitura/fala. Todos executaram a tarefa solicitada de forma intuitiva. Este dado é importante, pois verificamos que, na maioria dos casos em que os leitores conseguiram marcar prosodicamente sua intenção interpretativa e esta foi reconhecida e utilizada pelos ouvintes em suas escolhas de aposição, as pistas empregadas foram as mesmas (elevação do pitch nos SN's e no Atributo, pausa silenciosa e alongamento). Mesmo não sendo treinado, o leitor utiliza parâmetros prosódicos que podemos chamar de "padrões" para a língua. E, para o ouvinte, quando a pista prosódica é clara, não é deixada de lado no processamento da informação. Todas as vezes que o leitor conseguiu empregar uma pista prosódica clara, esta foi reconhecida pelo ouvinte e a interpretação do mesmo foi direcionada pela prosódia.

\section{Considerações finais}

Esse experimento nos faz voltar à seguinte questão, levantada por Marcus MAIA(Instituto da ABRALIN 2005): Que tipos de informação são utilizados no parsing? Sintática? Semântica? Pragmática? E acrescentamos: Prosódica? Lexical?

Os resultados percentuais neutros observados na interpretação das pistas da Leitura Espontânea própria (TAB. 3), comparados aos resultados do Teste de Percepção de Leitura Intencional (GRAF. 3 a 6), confirmam que, de fato, há fatores de ordem lingüística e não-lingüística influenciando nas escolhas de Aposição, mas que a produção prosódica intencional melhora os índices de interpretação da sentença com Aposição Não-Local, contrariando o princípio sintático tido como universal para o processamento de sentenças.

Interpretamos esse resultado como um indício de que as pistas prosódicas introduzidas atuam no momento do processamento da sentença, ou seja, no parsing. Cabe dizer que esse procedimento é um experimento off-line, e não pretende dizer sobre as ativações mentais no momento, on-line, do processamento. 
O que fizemos aqui foi uma leitura possível desses resultados, baseados em outros experimentos semelhantes que apontam para a importância da informação prosódica no parsing, como previsto pela HPI.

Estamos, no momento, preparando um novo experimento, manipulando, em laboratório, pistas prosódicas das sentenças utilizadas até aqui, com o intuito de obter uma interpretação única. A partir disso, poderemos, então, sugerir um padrão prosódico adequado para desfazer a ambigüidade estrutural em sentenças declarativas do tipo SN1-SV-SN2-Atributo, do PB.

\section{Agradecimentos}

Agradecemos as sugestões de alguns leitores anônimos desses experimentos (pareceristas), que emitiram opiniões por vezes contrastantes sobre nossa proposta, mas todas com o intuito de melhoria do texto e de aprimoramento dos métodos aplicados. Sem dúvida, o artigo agora, seguindo tais sugestões, está mais estruturado e claro. As falhas que persistem são de nossa inteira responsabilidade.

\section{Notas}

* Doutoranda do Programa de Pós-Graduação em Estudos Lingüísticos daFALE/UFMG. ** Professor titular da FALE/UFMG, na Área de Lingüística Teórica e Descritiva.

${ }^{1}$ Parser ou analisador sintático de frases é termo originário do latim (pars $=$ parte) e se refere aos procedimentos mentais que determinam a estrutura de uma frase, parte integrante dos processos de produção e compreensão da linguagem.

${ }^{2}$ Para mais detalhes e indicação bibliográfica, conf. Maia \& Finger, 2005, p.11-28.

${ }^{3}$ Tradução de Dillinger, 1992.

4 "Aponha o material de entrada no marcador sintagmático que estiver sendo construído usando a menor quantidade de nós consistentes com as regras de boa formação da gramática".

5 "Quando possível, aponha os itens lexicais, que vão sendo encontrados, à oração ou sintagma correntemente sendo processado, ou seja, o nó não-terminal mais baixo possível dominando o último item analisado".

6 "Na leitura silenciosa, um contorno prosódico default é projetado no estímulo, e pode influenciar a resolução da ambigüidade sintática. Tudo mais permanecendo constante, o parser favorece a análise sintática associada ao contorno prosódico mais natural (default) para a construção." 
${ }^{7}$ Estamos chamando estas "pistas" prosódicas de "segmentações" porque, na verdade, elas apontam para um "parseamento" (divisão da frase em partes). A escolha dessas pistas decorreu da própria análise dos dados que as apontou como as estratégias de processamento da ambigüidade, as mesmas encontradas em estudo semelhante de Chow (2005), para o cantonês.

${ }^{8}$ Técnica conhecida na literatura psicolingüística como self-paced reading task, em que os sujeitos lêem palavras, sintagmas, orações, frases ou textos, em tela de computador, pressionando uma tecla para aparecer cada pedaço, conforme o experimento.

${ }^{9}$ Esse sistema de combinações, conhecido como "quadrado latino", é preparado em uma tabela quadriculada, na qual todos os dados são distribuídos eqüitativamente contemplando todos os grupos de informantes, de tal forma que um mesmo dado não seja submetido a informante de um outro grupo.

${ }^{10}$ Para maiores detalhes sobre a METODOLOGIA do experimento, consultar Magalhães e Maia (2006a, b).

${ }^{11}$ O teste estatístico de proporções verifica se 195 em 240 é significativamente maior que 171 em 240, indicando que esse tipo de segmentação reforça a Aposição Local.

${ }^{12} \mathrm{O}$ teste estatístico de proporções verifica se $145 \mathrm{em} 240$ é significativamente menor que 171 em 240, indicando que esse tipo de segmentação diminui a Aposição Local.

${ }^{13}$ Os sujeitos do experimento foram alunos do Curso de Letras da FALE/UFMG, sem queixa auditiva.

${ }^{14}$ Para uma exemplificação de pistas prosódicas, confira a INTRODUÇÃO deste artigo; as porcentagens de pistas utilizadas nas leituras estão nas tabelas 4 e 5 seguintes.

\section{Referências Bibliográficas}

BOERSMA, P.; WEENICK, D. PRAAT: doing phonetics by computer (version:4.2.07), 2005. http://www.praat.org/.

CHOW, Ivan. Prosodic cues for syntactically-motivated junctures. Proceedings of the Interspeech 2005 Conference. Lisboa.

CUETOS F.; MITCHELL, D. C. Cross-linguistic differences in parsing: restrictions on the use of the Late Closure strategy in Spanish. Cognition 30, p. 73-105, 1988.

DILLINGER, Mike. Parsing Sintático. Boletim da ABRALIN, n. 13, p.30-42, 1992.

FODOR, J. D. Learning to parse? Journal of Psycholinguistic Research, 27, 2, p. 285-319, 1998. 
FODOR, J.D. Psycholinguistics cannot escape prosody. Trabalho apresentado em Speech Prosody 2002, Aix-en-Provence, France, April 11-13. Disponível em: $<$ http://www.lpl.univ-aix.fr/sp2002/pdf/ fodor.pdf $>$.

FODOR, J. D. A psicolinguística não pode escapar da prosódia. In: MAIA, M.; FINGER, I. Processamento da Linguagem. Porto Alegre: Educat, 2005. p. 91-110.

FRAZIER, L. On comprehending sentences: syntactic parsing strategies. 1979. Tese (Doutorado) - University of Connecticut (reproduzida por Indiana University Linguistics Club), 1979.

FRAZIER, L.; FODOR, J. D. The Sausage Machine: A new two-stage parsing model. Cognition 6, p.291-326, 1978.

FRAZIER, L.; RAYNER, K. Making and correcting errors during sentence comprehension: Eye movements in the analysis of structurally ambiguous sentences. Cognitive Psychology, 14, p. 178-210, 1982.

LOURENÇO-GOMES, M. C.; MAIA, Marcus; MORAES, João A. Prosódia implícita na leitura silenciosa: um estudo com orações relativas estruturalmente ambíguas. In: MAIA, M.; FINGER, I. Processamento da linguagem. Porto Alegre: Educat, 2005. p.131-162.

LOURENÇO-GOMES, M. C. Efeito de comprimento do constituinte na interpretação final de orações relativas estruturalmente ambíguas: um estudo baseado na 'Hipótese da Prosódia Implícita'. 2003. Dissertação (Mestrado em Lingüística) - FL/UFRJ, Rio de Janeiro, 2003.

LOVRIC $\breve{C}$. Implicit prosody in silent reading: relative clause attachment in Croatian. 2003. Tese (Doutorado) - City University of New York - CUNY, 2003.

MAGALHÃES, J. Olímpio; MAIA, Marcus. Implicit Prosody effects on the attachment of attributes to NPs in Brazilian Portuguese. Poster apresentado na $19^{a}$ Annual Cuny Conference on Human Sentence Processing, realizada na CUNY, Nova York, 23-25 mar. 2006a. Publicado resumo no boletim do congresso, p. 122.

MAGALHÃES, J. Olímpio; MAIA, Marcus. Pistas prosódicas implícitas na resolução de ambigüidades sintáticas: um caso de adjunção de atributos. Revista da ABRALIN, v. 5, n. 1 e 2, p. 143-167, 2006b.

MAIA, M.; FINGER, I. Processamento da Linguagem. Porto Alegre: Educat, 2005. 